Correction

\title{
Correction: Li et al. Multidrug-Resistant Streptococcus agalactiae Strains Found in Human and Fish with High Penicillin and Cefotaxime Non-Susceptibilities. Microorganisms 2020, 8, 1055
}

\author{
Carmen Li D, Dulmini Nanayakkara Sapugahawatte (D), Ying Yang, Kam Tak Wong, Norman Wai Sing Lo and \\ Margaret Ip *iD
}

check for

updates

Citation: Li, C.; Nanayakkara Sapugahawatte, D.; Yang, Y.; Wong, K.T.; Lo, N.W.S.; Ip, M. Correction: Li et al. Multidrug-Resistant Streptococcus agalactiae Strains Found in Human and Fish with High Penicillin and Cefotaxime

Non-Susceptibilities. Microorganisms 2020, 8, 1055. Microorganisms 2021, 9 , 1198. https://doi.org/10.3390/

microorganisms 9061198

Received: 27 May 2021

Accepted: 31 May 2021

Published: 1 June 2021

Publisher's Note: MDPI stays neutral with regard to jurisdictional claims in published maps and institutional affiliations.

Copyright: (c) 2021 by the authors. Licensee MDPI, Basel, Switzerland. This article is an open access article distributed under the terms and conditions of the Creative Commons Attribution (CC BY) license (https:// creativecommons.org/licenses/by/ $4.0 /)$.
Department of Microbiology, Prince of Wales Hospital, The Chinese University of Hong Kong, Hong Kong Special Administrative Region (HKSAR), Hong Kong, China; 2carmen.li@cuhk.edu.hk (C.L.); 1155085653@link.cuhk.edu.hk (D.N.S.); yingyang@cuhk.edu.hk (Y.Y.); kamtakwong@cuhk.edu.hk (K.T.W.); normanlo@cuhk.edu.hk (N.W.S.L.)

* Correspondence: margaretip@cuhk.edu.hk; Tel.: +852-3505-3333; Fax: +852-2647-3227

The authors would like to make the following correction to the published paper [1].

There is a mistake in the last sentence of the second paragraph in Section 3.2 Antimicrobial Susceptibility Testing. in F49".

The sentence should read "ARGs conferring resistance to macrolide (mreA) was found

This change will not alter the conclusions drawn in the paper.

Funding: This research was funded by the Health and Medical Research Fund from the Food and Health Bureau, Hong Kong Special Administrative Region (HMRF grant no.: 17160212 (PI: M.I.).

Conflicts of Interest: The authors declare no conflict of interest.

\section{Reference}

1. Li, C.; Sapugahawatte, D.N.; Yang, Y.; Wong, K.T.; Lo, N.W.S.; Ip, M. Multidrug-Resistant Streptococcus agalactiae Strains Found in Human and Fish with High Penicillin and Cefotaxime Non-Susceptibilities. Microorganisms 2020, 8, 1055. [CrossRef] [PubMed] 